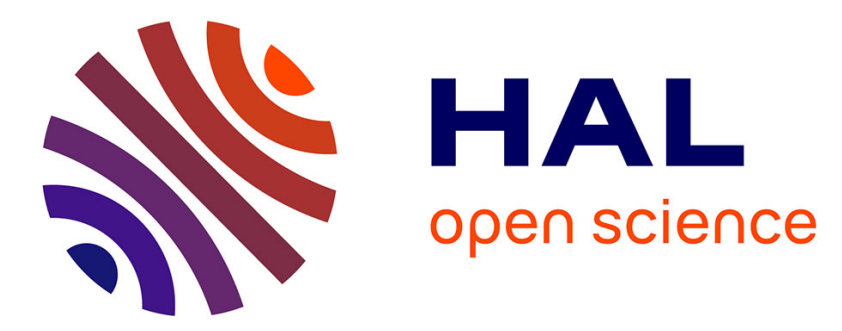

\title{
Epoxidation Processes by Pyridoxal Dioxomolybdenum(VI) (Pre)Catalysts Without Organic Solvent
}

Jana Pisk, Dominique Agustin, Višnja Vrdoljakc, Rinaldo Poli

\section{- To cite this version: \\ Jana Pisk, Dominique Agustin, Višnja Vrdoljakc, Rinaldo Poli. Epoxidation Processes by Pyridoxal Dioxomolybdenum(VI) (Pre)Catalysts Without Organic Solvent. Advanced Synthesis and Catalysis, 2011, 353 (16), pp.2910-2914. 10.1002/adsc.201100439 . hal-03157929}

\section{HAL Id: hal-03157929 \\ https://hal.science/hal-03157929}

Submitted on 3 Mar 2021

HAL is a multi-disciplinary open access archive for the deposit and dissemination of scientific research documents, whether they are published or not. The documents may come from teaching and research institutions in France or abroad, or from public or private research centers.
L'archive ouverte pluridisciplinaire HAL, est destinée au dépôt et à la diffusion de documents scientifiques de niveau recherche, publiés ou non, émanant des établissements d'enseignement et de recherche français ou étrangers, des laboratoires publics ou privés. 
DOI: 10.1002/adsc.200((will be filled in by the editorial staff))

\title{
Epoxidation Processes by Pyridoxal Dioxomolybdenum(VI) (Pre)Catalysts Without Organic Solvent
}

\author{
Jana Pisk ${ }^{\mathrm{a}, \mathrm{b}, \mathrm{c}}$, Dominique Agustin ${ }^{\mathrm{a}, \mathrm{b}, *}$, Višnja $\operatorname{Vrdoljak}^{\mathrm{c}}$, Rinaldo Poli ${ }^{\mathrm{b}, \mathrm{d}}$ \\ a Université de Toulouse; Institut Universitaire de Technologie Paul Sabatier, Département de Chimie, Av. Georges \\ Pompidou, BP 20258, F-81104 Castres Cedex, France. \\ Phone: (+33)-5-6362-1172; e-mail: dominique.agustin@iut-tlse3.fr \\ b CNRS; LCC (Laboratoire de Chimie de Coordination); Université de Toulouse; UPS, INPT, 205, route de Narbonne, \\ F-31077 Toulouse, France \\ c Department of Chemistry, Faculty of Science, University of Zagreb, Horvatovac, 102a, 10000 Zagreb, Croatia. \\ d Institut Universitaire de France, 103, bd Saint-Michel, 75005 Paris, France
}

Received: ((will be filled in by the editorial staff))

Supporting information for this article is available on the WWW under http://dx.doi.org/10.1002/adsc.200\#\#\#\#\#.((Please delete if not appropriate))

\begin{abstract}
Molybdenum(VI) pyridoxal thiosemicarbazonato complexes have proved to be efficient catalysts in olefin epoxidation of cyclooctene by aqueous TBHP in absence of organic solvent. High activity and selectivity have been obtained with a catalyst loading of just $0.05 \%$ molybdenum in the case of one mononuclear (pre)catalyst (TOF 3360 $\mathrm{h}^{-1}$ ) under solvent-free conditions. The influence of methanol on activity and selectivity has been studied.
\end{abstract}

Keywords: Epoxidation; Molybdenum; Pyridoxal ligands; Homogeneous catalysis; Solvent-free

Epoxides, as precious precursors in organic synthesis, can be easily obtained from alkenes by the use of strong organic oxidants $(m \text {-CPBA, } \mathrm{NaClO})^{[1]}$ or smoother oxidants (THBP, $\left.\mathrm{H}_{2} \mathrm{O}_{2}\right)^{[2]}$ with the assistance of metal-based catalysts (Fe, Mn, Re, Mo, $\mathrm{V}, \mathrm{W}) \cdot{ }^{[2,3]}$ Among these metals, molybdenum attracts most of the attention. ${ }^{[3-6]}$ Different stable $\mathrm{Mo}^{\mathrm{VI}}$ complexes have been used as pre-catalysts. ${ }^{[2 \mathrm{a}, 2 \mathrm{~b}, 3-6]}$ Most of the investigated processes are performed in chlorinated solvents with catalyst loadings as high as $1 \%$ Mo. Solvent recovery asks extra efforts and costs that could be eliminated by the application of greener processes. Dioxomolybdenum(VI) complexes with tridentate Schiff base $(O N O)$ ligands are interesting candidates because of their facile preparation, structural flexibility, and stability; several of such complexes have already been used as epoxidation (pre)catalysts. ${ }^{[4,5]}$ On the other hand, tridentate ligands with an ONS donor set are much less common. There is apparently only one report of a catalyzed epoxidation process carried out with a $\mathrm{Mo}^{\mathrm{VI}}$ complex containing an $O N S$ ligand. ${ }^{[6]}$

In the aim of developing cleaner processes, ${ }^{[7]}$ we have investigated a few recently published ${ }^{[8]} \mathrm{Mo}^{\mathrm{VI}}$ (pre)catalysts containing pyridoxal-based ONS ligands for olefin epoxidation by aqueous TBHP, without addition of extra organic solvent. Emphasis is placed on the low Mo content ( $0.05 \%$ Mo vs. olefin) and the solvent-free operating conditions.

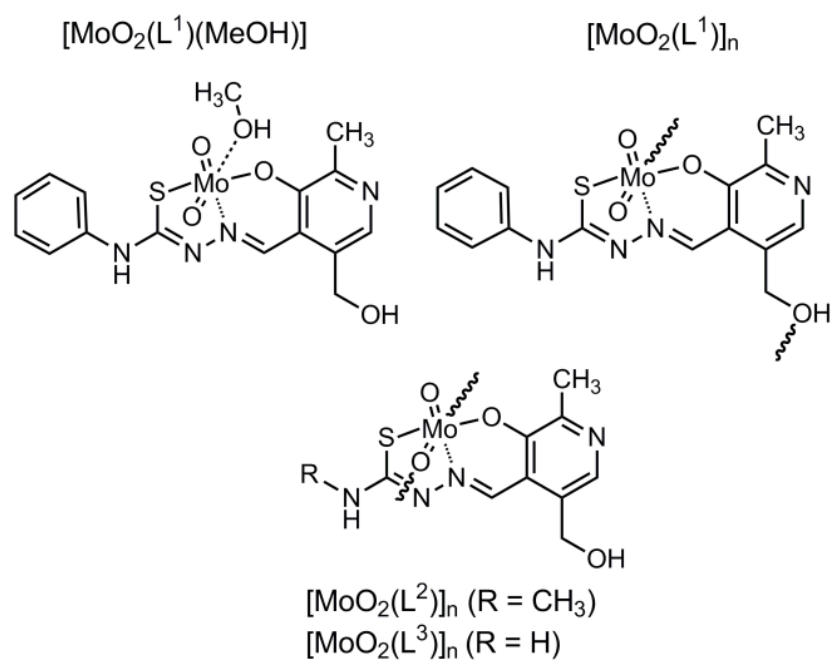

Scheme 1. Mo(VI) pyridoxal thiosemicarbazonato complexes used as (pre)catalysts.

Pyridoxal thiosemicarbazonato ligands have been distinguished as a new class of ligands presenting antiviral and antitumoral activity when complexed to transition metals. ${ }^{[9]}$ In the recently reported molybdenum complexes, ${ }^{[8]}$ these ligands coordinate the central metal atom in the doubly deprotonated form through the oxygen, sulfur and nitrogen atoms. Mononuclear $\left[\mathrm{MoO}_{2}\left(\mathrm{~L}^{1}\right)(\mathrm{MeOH})\right]$ and polynuclear $\left[\mathrm{MoO}_{2}\left(\mathrm{~L}^{1-3}\right)\right]_{\mathrm{n}}$ species (see Scheme 1) are available as previously described. ${ }^{[8]}$ The $\left[\mathrm{MoO}_{2}\left(\mathrm{~L}^{1}\right)\right]_{\text {n }}$ polymer can be converted to the corresponding mononuclear $\left[\mathrm{MoO}_{2}\left(\mathrm{~L}^{1}\right)(\mathrm{MeOH})\right]$ when dissolved in $\mathrm{MeOH}$, 
whereas the opposite transformation occurs upon treating the mononuclear methanol adduct with suitable solvent such as acetonitrile (Scheme 2). Stable $\mathrm{MeOH}$ adducts derived from the polymers containing the $\mathrm{L}^{2}$ and $\mathrm{L}^{3}$ ligands, on the other hand, could not be isolated.

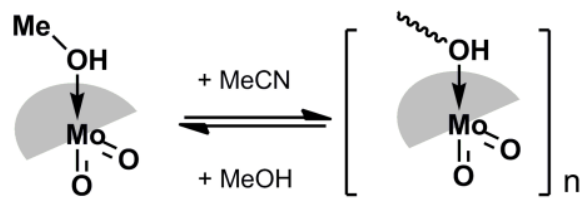

Scheme 2. Interconversion of $\left[\mathrm{MoO}_{2}\left(\mathrm{~L}^{1}\right)(\mathrm{MeOH})\right]$ and $\left[\mathrm{MoO}_{2}\left(\mathrm{~L}^{1}\right)\right]_{\mathrm{n}}$ by exposure to a different solvent (the grey half-sphere indicates the $O N S \mathrm{~L}^{1}$ ligand).

Although many previous contributions report on the catalytic activity of molybdenum species in alkene epoxidation, ${ }^{[3,4,10]}$ only few deal with Mothiosemicarbazonato complexes. ${ }^{[6,11]}$ Furthermore, the typical Mo:substrate ratio is $1: 100^{[12]}$ and nearly all epoxidation reactions were performed in organic solvents. $^{[2 \mathrm{a}-\mathrm{b}, 4,6,10,12-14]}$ We have recently observed a solvent-free process using similar complexes (with a variety of $O N O$ ligands), with high activity and high selectivity for the epoxidation of cyclooctene (for instance, up to $98 \%$ when using $\left[\mathrm{MoO}_{2}(\mathrm{SAP})\right]_{2}$, SAP $=N$-salicylidene-2 aminophenolato), only when using a Mo:substrate ratio of $1: 100 .^{[5]}$ With a lower Mo:substrate ratio $(1: 2000)$, the same $\left[\mathrm{MoO}_{2}(\mathrm{SAP})\right]_{2}$ complex gave a substantially weaker selectivity $(68 \%$, see SI). Pyridoxal-based ONS Mo ${ }^{\mathrm{VI}}$ complexes have now been tested under the same conditions and with low $0.05 \%$ Mo catalyst loading and we herein communicate the corresponding results.

The investigated $\left[\mathrm{MoO}_{2}\left(\mathrm{~L}^{1}\right)(\mathrm{MeOH})\right]$ and $\left[\mathrm{MoO}_{2}\left(\mathrm{~L}^{1-3}\right)\right]_{\mathrm{n}}$ complexes are sparingly soluble in cyclooctene and insoluble in water at room temperature, but dissolve completely in the organic phase after addition of aqueous TBHP at $80{ }^{\circ} \mathrm{C}$. The aqueous phase was colourless and the organic one yellowish, indicating that the catalyst is mainly confined in the organic phase. The epoxidation results are shown in Fig. 1.

The selectivity is very high (84-99\%) for all tested molybdenum compounds, following the order $\left[\mathrm{MoO}_{2}\left(\mathrm{~L}^{3}\right)\right]_{\mathrm{n}} \sim\left[\mathrm{MoO}_{2}\left(\mathrm{~L}^{1}\right)(\mathrm{MeOH})\right]>\left[\mathrm{MoO}_{2}\left(\mathrm{~L}^{2}\right)\right]_{\mathrm{n}}>$ $\left[\mathrm{MoO}_{2}\left(\mathrm{~L}^{1}\right)\right]_{\mathrm{n}}$. The epoxide yield is moderate to very good after $6 \mathrm{~h}$ (43-94\%), with the activity and yield following the order $\left[\mathrm{MoO}_{2}\left(\mathrm{~L}^{1}\right)(\mathrm{MeOH})\right] \gg$ $\left[\mathrm{MoO}_{2}\left(\mathrm{~L}^{3}\right)\right]_{\mathrm{n}} \sim\left[\mathrm{MoO}_{2}\left(\mathrm{~L}^{2}\right)\right]_{\mathrm{n}} \gg\left[\mathrm{MoO}_{2}\left(\mathrm{~L}^{1}\right)\right]_{\mathrm{n}}(\mathrm{Fig} .2)$. The relevance of the ONS coordination is confirmed by the fact that complex $\left[\mathrm{MoO}_{2}(\mathrm{acac})_{2}\right]$ gave poorer results while the $\mathrm{H}_{2} \mathrm{~L}^{1-3}$ ligands alone were not active at all.

The initial turnover frequencies $\left(\mathrm{TOF}_{20 \mathrm{~min}}\right)$ for the tested compounds (see SI) are very good with 0.05 Mo \% only, the lowest being $645 \mathrm{~h}^{-1}$ for $\left[\mathrm{MoO}_{2}\left(\mathrm{~L}^{1}\right)\right]_{\mathrm{n}}$ and the highest one $3360 \mathrm{~h}^{-1}$ for $\left[\mathrm{MoO}_{2}\left(\mathrm{~L}^{1}\right)(\mathrm{MeOH})\right]$. Under these conditions, the $\left[\mathrm{MoO}_{2}(\mathrm{SAP})\right]_{2}$ compound gives a TOF of $453 \mathrm{~h}^{-1}$ with lower selectivity $(68 \%)$. These results may be compared with those of the organometallic precursor $\left[\mathrm{CpMo}(\mathrm{CO})_{2}\left(\eta^{3}-\mathrm{C}_{3} \mathrm{H}_{5}\right)\right]$, used at $1 \%$ Mo loading, for which a TOF of $97 \mathrm{~h}^{-1}$ was reported under the same conditions (aqueous TBHP), and $310 \mathrm{~h}^{-1}$ using TBHP in decane. ${ }^{[12 b]}$ On the other hand, TOFs up to 13000 $\mathrm{h}^{-1}$ were claimed using sugar based $O N O$ ligands. ${ }^{[4]}$ Our results are promising in terms of (i) low Mo loading, (ii) solvent free process (iii) overall performance (activity, selectivity) for " $\mathrm{MoO}_{2} \mathrm{~L}$ " type complexes, $(\mathrm{L}=$ tridentate ligand $)$.

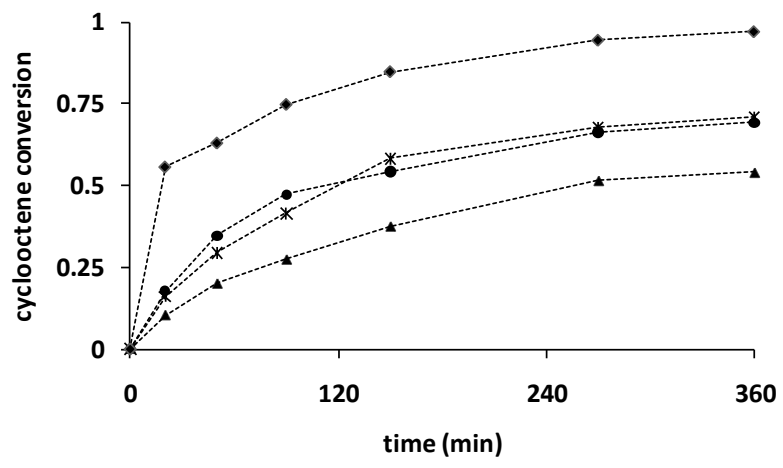

Figure 1. Kinetic profile of converted cyclooctene $v s$. time with $\mathrm{Mo}(\mathrm{VI}) \quad$ (pre)catalysts: $\bullet\left[\mathrm{MoO}_{2}\left(\mathrm{~L}^{1}\right)(\mathrm{MeOH})\right]$, $\Delta\left[\mathrm{MoO}_{2}\left(\mathrm{~L}^{1}\right)\right]_{\mathrm{n}}, *\left[\mathrm{MoO}_{2}\left(\mathrm{~L}^{2}\right)\right]_{\mathrm{n}}, \bullet\left[\mathrm{MoO}_{2}\left(\mathrm{~L}^{3}\right)\right]_{\mathrm{n}}$. Conditions: substrate $/($ pre $)$ catalyst $=2000: 1 ; \mathrm{T}=80{ }^{\circ} \mathrm{C}$.

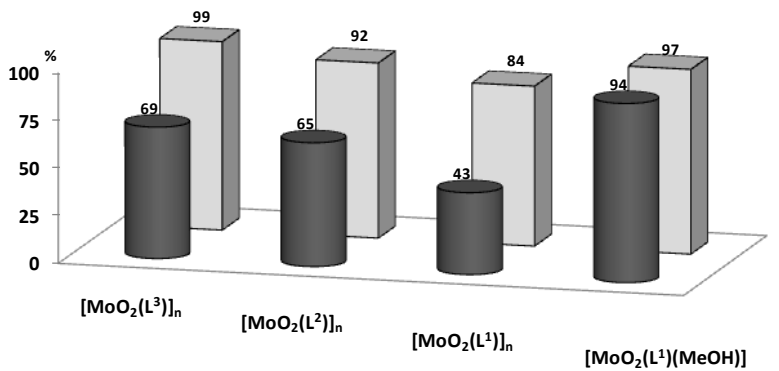

Figure 2. Results of catalyzed cyclooctene epoxidation in the presence of aqueous TBHP after $6 \mathrm{~h}$ at $80^{\circ} \mathrm{C}$. Epoxide selectivity (light parallelepipeds); epoxide yield (dark cylinders).

The $\left[\mathrm{MoO}_{2}\left(\mathrm{~L}^{1}\right)(\mathrm{MeOH})\right]$ system yields a TOF 5 times higher than its corresponding polynuclear compound $\left[\mathrm{MoO}_{2}\left(\mathrm{~L}^{1}\right)\right]_{\mathrm{n}}$. In order to clarify the role of methanol, additional experiments were carried out using different $\mathrm{MeOH} /\left[\mathrm{MoO}_{2}\left(\mathrm{~L}^{1}\right)\right]_{\mathrm{n}}$ ratios. Excess methanol ( $\mathrm{m}$ equiv $v s$. Mo) was added at the beginning of the reaction before the TBHP addition, Exp. $\mathbf{A}_{\mathbf{m}}(\mathbf{m}=0,1,12.5,25,50)$. The kinetic profiles of these experiments are shown in Fig. 3, whereas Fig. 4 compares the initial TOFs and the final conversions. As pointed out earlier for catalytic oxidations with $\mathrm{Mo}^{\mathrm{VI}}$ complexes coordinated with two bidentate ligands, ${ }^{[4 \mathrm{~b}]}$ the presence of methanol as a solvent should increase the catalytic activity because of the 
resulting higher polarity of the reaction medium. Experiments $\mathbf{A}_{1 \leq \mathrm{m} \leq 25}$ indeed show greater activity than experiment $\mathbf{A}_{0}$, but the activity decreases for $\mathrm{MeOH}$ amounts greater than 1 equiv. until falling below the level of $\mathbf{A}_{\mathbf{0}}$ for a large excess (experiment A50). The quickest and most efficient reaction occurs in case of $\mathbf{A}_{1}$, corresponding to the stoichiometry of the mononuclear methanol adduct.

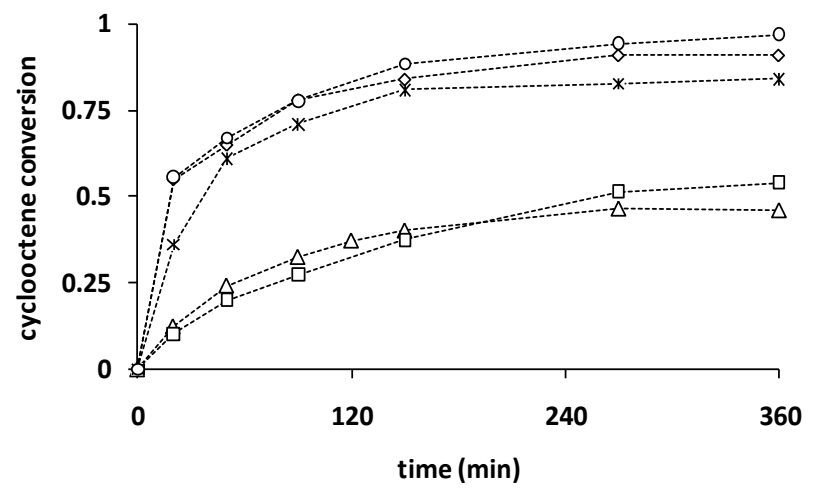

Figure 3. Kinetic profile of converted cyclooctene $v s$. time with $\left[\mathrm{MoO}_{2}\left(\mathrm{~L}^{1}\right)\right]_{\mathrm{n}}$ with different $\mathrm{MeOH} / \mathrm{Mo}$ ratio: from top to bottom ( $\mathrm{t}=360 \mathrm{~min}): \mathrm{A}_{1}(\mathrm{\circ}), \mathrm{A}_{12.5}(\diamond), \mathrm{A}_{25}(*), \mathrm{A}_{0}(\square)$, $\mathrm{A}_{50}(\Delta)$.

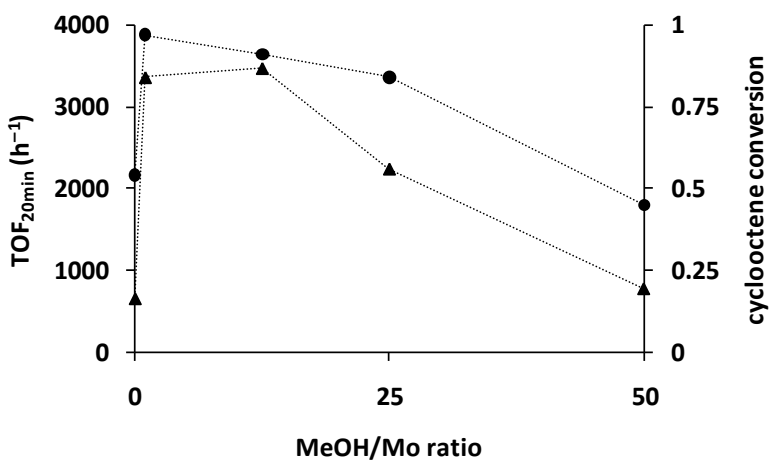

Figure 4. Dependence of initial TOFs $(\bullet)$ and cyclooctene conversion $(\boldsymbol{\Delta})\left(\right.$ after $6 \mathrm{~h}$ at $80{ }^{\circ} \mathrm{C}$ ) on the $\mathrm{MeOH} / \mathrm{Mo}$ ratio with the $\left[\mathrm{MoO}_{2}\left(\mathrm{~L}^{1}\right)\right]$ complex.

Another interesting experiment $\left(\mathbf{B}_{50}\right)$ was carried out by running experiment $\mathbf{A}_{\mathbf{0}}$ as above, but with the addition of 50 equivalents of $\mathrm{MeOH}$ after $90 \mathrm{~min}$ from the beginning of the reaction. The kinetic profile of this experiment is shown in Fig. 5, in comparison with those of experiments $\mathbf{A}_{\mathbf{0}}$ and $\mathbf{A}_{50}$. As expected, $\mathbf{B}_{50}$ initially follows the same profile as that of the polynuclear catalyst without methanol $\left(\mathbf{A}_{\mathbf{0}}\right)$, and the methanol addition provokes a sudden change of behavior, continuing along the same qualitative profile as experiment $\mathbf{A}_{\mathbf{5 0}}$ after 120 minutes.

These results indicate that, in apparent contrast with the literature suggestions, the solvent effect of the $\mathrm{MeOH}$ addition is not acceleration but rather slowdown. A possible interpretation of this effect is to invoke a $\mathrm{MeOH}$ dissociation equilibrium from the mononuclear $\mathrm{MeOH}$ adduct, liberating a coordination site to yield the catalytically active pentacoordinated $\left[\mathrm{MoO}_{2}\left(\mathrm{~L}^{1}\right)\right]$ species, as indicated in Scheme 3. On the other hand, rationalizing the positive effect of a single $\mathrm{MeOH}$ equivalent relative to the polymeric species is less straightforward. It must be noted that both catalysts dissolve completely in the reaction medium at the beginning of the experiment. This suggests that the $\left[\mathrm{MoO}_{2}\left(\mathrm{~L}^{1}\right)\right]_{\mathrm{n}}$ complex probably does not retain a polynuclear structure in the catalytic medium. However, it is likely to be present in a dinuclear or oligonuclear soluble form, with the sixth coordination site of the $\left[\mathrm{MoO}_{2}\left(\mathrm{~L}^{1}\right)\right]$ fragment occupied by a dangling hydroxymethyl group from the neighbouring complex. ${ }^{[15]}$ Presumably for entropic reasons, access to the catalytically active 5-coordinate $\left[\mathrm{MoO}_{2}\left(\mathrm{~L}^{1}\right)\right]$ intermediate may be slower from this oligonuclear species relative to the mononuclear $\mathrm{MeOH}$ adduct. ${ }^{[16]}$ The fact that no induction time is observed for these experiments suggests that the precatalyst maintains its equilibrium with the catalytic intermediates throughout the process. Indeed, the fact that the two (pre)catalysts (mononuclear $\mathrm{MeOH}$ adduct and polymer) with the same ONS ligand display such different catalytic activity suggests that the pre-catalyst also corresponds to the catalyst resting state.

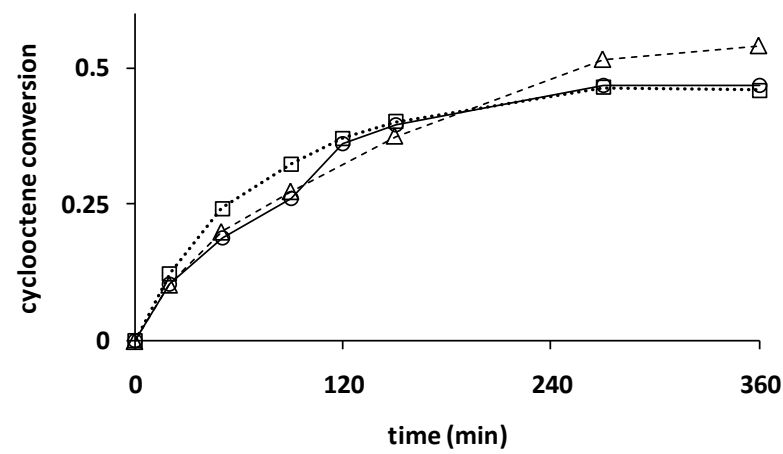

Figure 5. Kinetic profile of converted cyclooctene vs. time with $\left[\mathrm{MoO}_{2}\left(\mathrm{~L}^{1}\right)\right]_{\mathrm{n}}$ without methanol addition $\left(\mathrm{A}_{0},---\triangle---\right)$, with methanol addition at $\mathrm{t}=0 \mathrm{~min}$ (exp. $\left.\mathrm{A}_{50}, \cdots \square^{\cdots \cdots}\right)$, with methanol addition at $\mathrm{t}=90 \mathrm{~min}\left(\exp . \mathrm{B}_{50},-\mathrm{O}-\right)$.

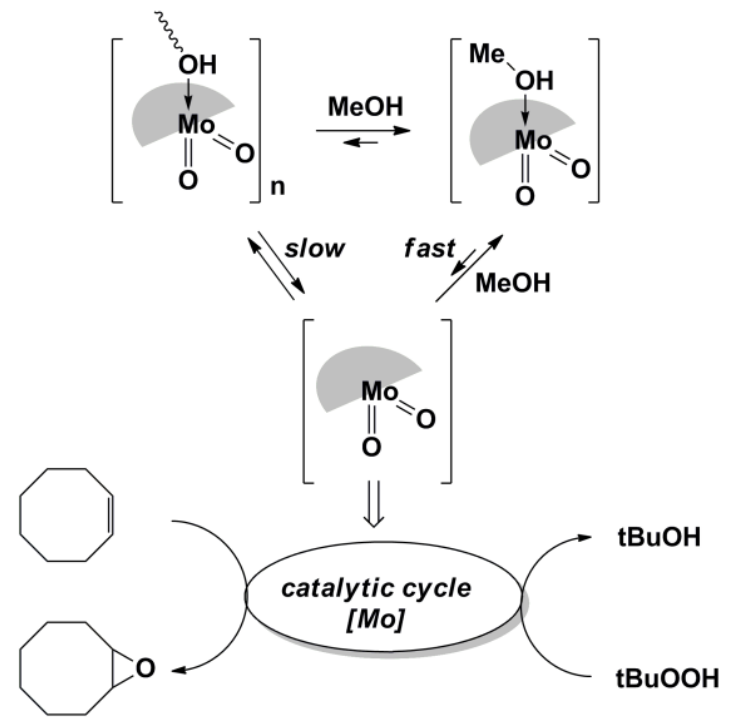

Scheme 3. Postulated equilibria with methanol between monomeric and polymeric structures in the mechanism of 
epoxidation with Mo(VI) (pre)catalysts (grey half-sphere indicates $O N S$ ligand).

We have also investigated the influence of methanol on the catalysis with the polynuclear compounds $\left[\mathrm{MoO}_{2}\left(\mathrm{~L}^{2}\right)\right]_{\mathrm{n}}$ (experiments $\mathbf{C}_{\mathbf{m}}$ ) and $\left[\mathrm{MoO}_{2}\left(\mathrm{~L}^{3}\right)\right]_{\mathrm{n}}\left(\right.$ experiments $\left.\mathbf{D}_{\mathbf{m}}\right)$, with $\mathbf{m}=0,1,25,50$. In this case, the effect of $\mathrm{MeOH}$ addition is much less dramatic, the difference of the various kinetic profiles for the same precatalyst being hardly greater than the experimental error (see Figures S1 and S2, respectively). Since complexes $\left[\mathrm{MoO}_{2}\left(\mathrm{~L}^{2}\right)\right]_{\mathrm{n}}$ and $\left[\mathrm{MoO}_{2}\left(\mathrm{~L}^{3}\right)\right]_{\mathrm{n}}$ adopt a different structure, as indicated in Scheme 1, with more labile $\mathrm{Mo}=\mathrm{O} \cdots$ Mo bridges, it can be assumed that access to the catalytically active pentacoordinated $\mathrm{MoO}_{2}\left(\mathrm{~L}^{2}\right)$ and $\mathrm{MoO}_{2}\left(\mathrm{~L}^{3}\right)$ species is equally fast from the polynuclear species and from the corresponding mononuclear $\mathrm{MeOH}$ adducts. The selectivity patterns for $\left[\mathrm{MoO}_{2}\left(\mathrm{~L}^{2}\right)\right]_{\mathrm{n}}$ and $\left[\mathrm{MoO}_{2}\left(\mathrm{~L}^{3}\right)\right]_{\mathrm{n}}$ are the same as in the case of $\left[\mathrm{MoO}_{2}\left(\mathrm{~L}^{1}\right)\right]_{\mathrm{n}}$ - the selectivity decreases as the amount of added methanol is increased.

A comparison of the activities of the polymeric precatalysts with different ligands (Fig. 6) shows greater activities for those precatalysts where the polymerisation mode involves $\mathrm{Mo}=\mathrm{O} \cdots$ Mo bridges $\left(\mathrm{L}^{2}\right.$ and $\left.\mathrm{L}^{3}\right),{ }^{[8]}$ relative to $\mathrm{L}^{1}$ which involves $\mathrm{Mo}(O N S$ $\mathrm{OH}) \cdot$ Mo bridges (see Scheme 1). Hence, it seems that the former kind of bridge is more labile than the latter.

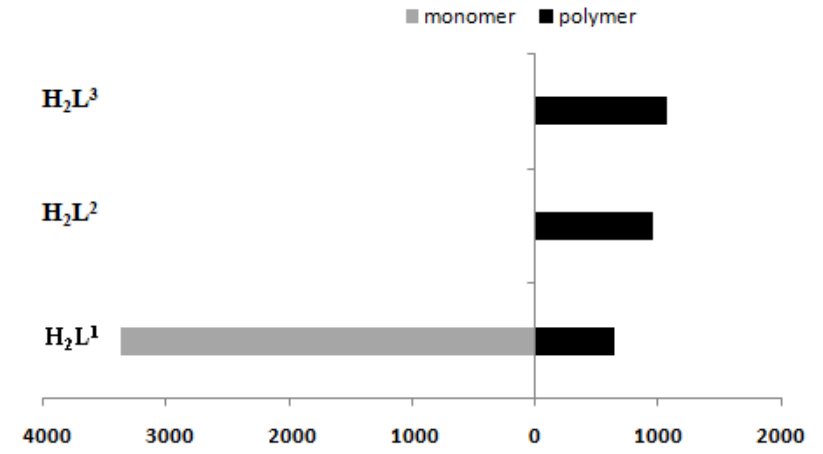

Figure 6. Comparative evaluation of $\mathrm{TOF}_{20 \mathrm{~min}}\left(\mathrm{~h}^{-1}\right)$ for epoxidation with " $\mathrm{MoO}_{2}\left(\mathrm{~L}^{1-3}\right)$ ") (pre)catalysts

In conclusion, for the first time, we have shown that $\mathrm{Mo}^{\mathrm{VI}}$ compounds with a pyridoxal moiety are efficient (pre)catalysts for epoxidation reactions by aqueous TBHP. $\left[\mathrm{MoO}_{2}\left(\mathrm{~L}^{1}\right)(\mathrm{MeOH})\right]$ seemed to be the best (pre)catalyst for the epoxidation of cyclooctene (highest TOF and TON values) in the absence of organic solvents. The comparison between the mononuclear $\mathrm{MeOH}$ adducts and the $\mathrm{MeOH}$-free polynuclear material and the effect of the $\mathrm{MeOH} / \mathrm{Mo}$ ratio for the experiments with added $\mathrm{MeOH}$ have revealed a new facet of the solvent effect on the catalytic activity of this family of compounds. Further experimental as well as computational investigations of the reaction mechanism are in progress, as well as a broader study of these catalytic systems for the epoxidation of other substrates.

\section{Experimental Section}

\section{Synthesis}

The syntheses and characterizations of monomeric $\left[\mathrm{MoO}_{2}\left(\mathrm{~L}^{1}\right)\left(\mathrm{CH}_{3} \mathrm{OH}\right)\right]$, polymeric complexes $\left[\mathrm{MoO}_{2}\left(\mathrm{~L}^{1-3}\right)\right]_{\mathrm{n}}$ had been reported previously. ${ }^{[8]}\left[\mathrm{MoO}_{2}(\mathrm{SAP})\right]_{2}{ }^{[5,17]}$ and $\left[\mathrm{MoO}_{2}(\mathrm{acac})_{2}\right]^{[18]}$ were prepared as described in literature. Cyclooctene, aqueous TBHP (70\%) and acetophenone were commercially available from Aldrich.

${ }^{1} \mathrm{H}$ spectra were recorded at $200.1 \mathrm{MHz}$ on a Bruker Advance DPX-200 spectrometer. Catalytic reactions were followed by gas chromatography on an Agilent 6890A chromatograph equipped with FID detector, a DB5-MS capillary column $(30 \mathrm{~m} \times 0.32 \mathrm{~mm} \times 0.25 \mu \mathrm{m})$. The GC parameters were quantified with authentic samples of the reactants and products. The conversion of cis-cyclooctene and the formation of cyclooctene oxide were calculated from calibration curves $\left(\mathrm{r}^{2}=0.999\right)$ relatively to acetophenone.

\section{General procedure for the epoxidation of cyclooctene by aqueous TBHP}

A mixture of cyclooctene $(2.76 \mathrm{~mL}, 20 \mathrm{mmol})$, acetophenone (internal reference) and Mo (pre)catalyst $(0.01 \mathrm{mmol})$ was stirred and heated up to $80{ }^{\circ} \mathrm{C}$ before addition of aqueous TBHP (70\%, $5.48 \mathrm{~mL}, 40 \mathrm{mmol})$. At this point, the mixture is an emulsion, but as the reaction progresses, two phases become clearly visible, a colorless aqueous one and a yellowish organic one. The reaction was followed for $6 \mathrm{~h}$ and aliquots were taken on required times. $0.1 \mathrm{~mL}$ of organic phase was taken from reaction media and mixed with $2 \mathrm{~mL}$ of $\mathrm{Et}_{2} \mathrm{O}$. To the solution was added small quantity of $\mathrm{MnO}_{2}$. The mixture was filtered through silica and analyzed by ${ }^{1} \mathrm{H}$ NMR in $\mathrm{CDCl}_{3}$.

Exp. $A_{m}, C_{m}$ and $D_{m}-$ Epoxidation of cyclooctene by the use of $\left[\mathrm{MoO}_{2}\left(\mathrm{~L}^{1-3}\right)\right]_{n}$ - addition of $\mathrm{MeOH}$ before $\mathrm{t}=\mathbf{0} \mathrm{min}$

The procedure was the same as the previous general procedure except that $\mathrm{m}$ equivalents of $\mathrm{MeOH}$ per Mo atom were added to reaction mixture together with $\left[\mathrm{MoO}_{2}\left(\mathrm{~L}^{1-3}\right)\right]_{\mathrm{n}}$. The reaction was followed by gas chromatography.

\section{Exp. $B_{50}$ - Epoxidation of cyclooctene by the use of $\left[\mathrm{MoO}_{2}\left(\mathrm{~L}^{1}\right)\right]_{\mathrm{n}}$ - addition of $\mathrm{MeOH}$ at $\mathrm{t}=90 \mathrm{~min}$}

The procedure was the same as for Exp. A one, but 50 eq. $\mathrm{MeOH}$ were added to the reaction mixture at $\mathrm{t}=90 \mathrm{~min}$.

\section{Acknowledgements}

All authors acknowledge CNRS, University Paul Sabatier (Institut Universitaire Paul Sabatier) and Ministry of Science and Technology of the Republic of Croatia (Grant No. 119-11913421082) for all research facilities. The fellowship of Jana Pisk was provided by the Ministry of Science and Technology of the Republic of Croatia, the National Foundation of Science and High Education of Croatia (03.01/O-3511-2010) and the French Embassy in Croatia. 


\section{References}

[1] a) R. N. McDonald, R. N. Steppel, J. E. Dorsey, Org. Synth. 1970, 50, 15-18; b) A. Corma, I. Dominguez, A. Domenech, V. Fornes, C. J. Gomez-Garcia, T. Rodenas, M. J. Sabater, J. Catal. 2009, 265, 238-244.

[2] a) P. M. Reis, C. A. Gamelas, J. A. Brito, N. Saffon, M. Gomez, B. Royo, Eur. J. Inorg. Chem., 2011, 5, 666-673;

b) C. Dinoi, M. Ciclosi, E. Manoury, L. Maron, L. Perrin, R. Poli, Chem. Eur. J. 2010, 16(31), 9572-9584; c) C. Cordelle, D. Agustin, J. C. Daran, R. Poli, Inorg. Chim. Acta 2010, 364, 144-149.

[3] a) K. A. Jorgensen, Chem. Rev. 1989, 89, 431-485; b) R. Sanz, M. R. Pedrosa, Curr. Org. Chem. 2009, 6(3), 239263 ; c) F. E. Kühn, A. M. Santos, M. Abrantes, Chem. Rev. 2006, 106, 2455-2475.

[4] a) J. Zhao, X. Zhou, A. M. Santos, E. Herdtweck, C. C. Romão, F. E. Kühn, Dalton Trans. 2003, 3736-3742; b) M. Bagherzadeh, L. Tahsini, R. Latifi, L. K. Woo, Inorg. Chim. Acta 2009, 362, 3698-3702; c) Y. Sui, X. Zeng, X. Fang, X. Fu, Y. Xiao, L. Chen, M. Li, S. Cheng, J. Mol. Catal. A Chem, 2007, 270(1-2), 61-67; d) D. D. Agarwal, J. Mol. Catal., 1988, 44(1), 65-72; e) D. D. Agarwal, S. Shrivastava, Polyhedron, 1988, 7(24), 2569-2573.

[5] J. Morlot, D. Agustin, R. Poli, manuscript in preparation.

[6] S. N. Rao, N. Kathale, N. N. Rao, K. N. Munshi, Inorg. Chim. Acta 2007, 360, 4010-4016.

[7] Green Separation Processes: Fundamentals and Applications : Eds. C. A. M. Alfonso, J. P. G. Crespo, P. A. Anastas, Wiley - VCH, Weinheim 2005, 1-32.

[8] V. Vrdoljak, J. Pisk, B. Prugovečki, D. MatkovićČalogović, Inorg. Chim. Acta 2009, 362, 4059-4064.
[9] a) M. Belicchi-Ferrari, F. Bisceglie C. Casoli, S. Durot, I. Morgenstern-Badarau, G. Pelosi, E. Pilotti, S. Pinelli, P. Tarasconi, J. Med. Chem. 2005, 48, 1671-1675; b) M. Belicchi Ferrari, G. Gasparri Fava, P. Tarasconi, R. Albertini, S. Pinelli, R. Starcich, J. Inorg. Biochem., 1994, $53,13-25$.

[10] P. J. Costa, M. J. Calhorda, F. E. Kühn, Organometallics 2010, 29, 303-311.

[11] M. Muthukumar, P. Viswanathamurthi, Cent. Eur. J. Chem. 2010, 8(1), 229-240.

[12] a) J. Fridgen, W. A. Herrmann, G. Eickerling, A. M. Santos, F. E. Kühn, J. Organomet. Chem. 2004, 689, 27522761; b) P. Neves, C. C. L. Pereira, F. A. A. Paz, S. Gago, M. Pillinger, C. M. Silva, A. A. Valente, C. R. Romão, I. S. Gonçalves, J. Organomet. Chem. 2010, 695, 2311-2319; c) P. M. Reis, C. A. Gamelas, J. A. Brito, N. Saffon, M. Gomez, B. Royo, Eur. J. Inorg. Chem. 2011, 666-673.

[13] F. Romano, A. Linden, M. Mba, C. Zonta, G. Licini, Adv. Synth. Catal. 2010, 352, 2937-2942.

[14] J. M. Sobczak, J. J. Ziołkowski, Appl. Cat. A, Gen. 2003, 248, 261-268.,

[15] a) V. Vrdoljak, B. Prugovečki, D. MatkovićČalogovic, J. Pisk, R. Dreos, P. Siega, Cryst. Growth Des. 2011, 11, 1244-1252; b) K. Aoki, N. Hu, H. Yamazaki, Inorg. Chim. Acta 1991, 186, 253-261.

[16] K. Užarevic, M. Rubčić, I. Đilović, Z. Kokan, D. Matković-Čalogović, M. Cindrić, Cryst. Growth Des. 2009, 9(12) 5327-5333.

[17] D. Agustin, C. Bibal, B. Neveux, J.-C. Daran, R. Poli, Z. Anorg. Allg. Chem. 2009, 635, 2120-2125.

[18] G. J.-J. Chen, J. W. McDonald, W. E. Newton, Inorg. Chem. 1976, 15, 2612-2615. 


\section{COMMUNICATION}

Epoxidation Processes by Pyridoxal

Dioxomolybdenum(VI) (Pre)Catalysts Without Organic Solvent

Adv. Synth. Catal. Year, Volume, Page - Page

Jana Pisk, Dominique Agustin*, Višnja Vrdoljak,

Rinaldo Poli

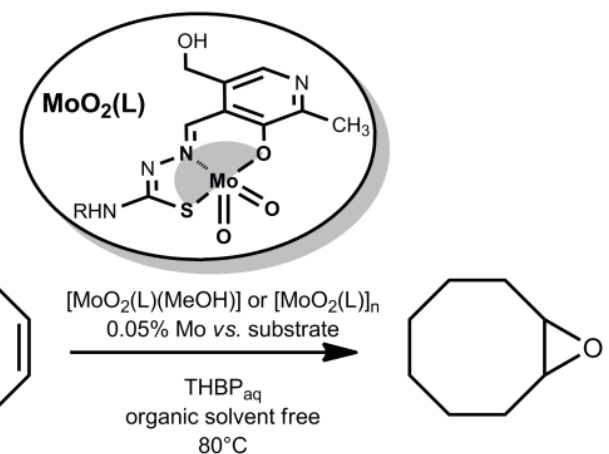

